\title{
POLÍTICAS PÚBLICAS DE PREVENÇÃO AO HIV/AIDS: UMA APROXIMAÇÃO ENTRE FRANÇA E BRASIL
}

PUBLIC POLICIES ON PREVENTION OF HIV/AIDS: CONNECTIONS BETWEEN FRANCE AND BRAZIL

LAS POLÍTICAS PÚBLICAS PARA PREVENIR EL VIH / SIDA: UN ACERCAMIENTO ENTRE FRANCIA Y BRASIL

Lara Brum de Calais*
Juliana Perucchi**

RESUMO

Este artigo resulta da realização de um estágio internacional do Programa de Cooperação Técnica Brasil-França, viabilizado pelo Departamento de DST, Aids e Hepatites Virais do Ministério da Saúde do Brasil. A pesquisa foi desenvolvida na instituição Cermes 3 (Paris/França), tendo como objetivo a análise do contexto francês de políticas públicas de prevenção ao HIV/aids e uma posterior aproximação com o contexto brasileiro. Para tanto, usou-se o "Plan National de Lutte contre le VIH/SIDA et les IST - 2010/2014" como documento de referência para a análise (baseado na análise do discurso de Michel Foucault) e a pesquisa documental como base metodológica. Pontos relevantes de análise foram levantados, como o direcionamento das ações de prevenção para públicos específicos no contexto francês, o que se caracteriza como ponto relevante de comparação com o Brasil, assim como a organização do sistema de "prevenção combinada" e o "sistema tripé de diagnóstico".

Palavras-chave: HIV/Aids. Política pública. França. Brasil.

\section{ABSTRACT}

The present article results from an international internship at the BrazilFrance Technical Cooperation Program, made possible by the STD, Aids and Viral Hepatitis Department of the Brazilian Ministry for Health. The research was conducted on the institution CERMES 3 (Paris/France), having as its goal the analysis of the French context concerning public policies on HIV/Aids prevention, and a later approximation with the Brazilian context. In order to do so, the "Plan National de Lutte contre le VIH/SIDA et les IST - 2010/2014" was used as a reference document for

\footnotetext{
Texto recebido em 16 de março de 2014 e aprovado para publicação em 19 de novembro de 2015.

Doutora em Psicologia pela Universidade Federal de Juiz de Fora (UFJF), professora dos cursos de Psicologia das faculdades Centro de Ensino Superior de Juiz de Fora (CES/JF) e Faculdade Machado Sobrinho. E-mail: laracalais@hotmail.com.

* Doutora, professora do Programa de Pós-Graduação em Psicologia da UFJF. E-mail: jperucchi@gmail.com.
} 
the analysis - from Michel Foucault's Discourse Analysis - and documental research as methodological basis. Relevant analysis points were raised, such as the targeting of specific groups in the prevention actions in the French context, which is characterized as a relevant point when compared to Brazil, as well as the organization of the system of "combined prevention" and the "system of diagnostic tripod".

Keywords: HIV/Aids. Public policies. France. Brazil.

\section{RESUMEN}

El artículo resulta de la realización de un periodo internacional de prácticas del Programa de Cooperación Técnica Brasil-Francia, viabilizado por el Departamento de ITS, Sida y Hepatitis Virales del Ministerio de Salud de Brasil. La investigación se realizó en la institución Cermes 3 (París/Francia), teniendo como objetivo el análisis del contexto francés de políticas públicas de prevención del $\mathrm{VIH} /$ sida y un abordaje posterior para el contexto brasileño. Se utilizó el "Plan National de Lutte contre le VIH/SIDA et les IST - 2010/2014" como un documento de referencia para el análisis (basado en el Análisis del Discurso de Michel Foucault) - y la investigación documental como base metodológica. Se plantearon algunos puntos relevantes de análisis, como el direccionamiento de las acciones de prevención para públicos específicos en el contexto francés, lo que se caracteriza como punto relevante de comparación con Brasil, así como la organización del sistema de "prevención combinada" y el "sistema trípode de diagnóstico".

Palabras clave: VIH/Sida. Políticas públicas. Francia. Brasil.

\section{INTRODUÇÃO: ENTENDENDO O CONTEXTO}

ste artigo resulta da realização de um estágio com intercâmbio de pesquisa no exterior, no âmbito do Programa de Cooperação Técnica Brasil-França, viabilizado pelo Ministério da Saúde do Brasil, por meio do Departamento de Doenças Sexualmente Transmissíveis (DST), Acquired Immunodeficiency Syndrome (Aids) e Hepatites Virais, e tem como objetivo a problematização acerca da constituição de políticas públicas de enfrentamento ao Human Immunodeficiency Virus (HIV)/aids nos dois países. Este programa caracterizase como um acordo bilateral que tem por objetivo qualificar e aprimorar políticas públicas no campo de DST, HIV, aids e hepatites virais, além de capacitar profissionais desses dois países.

Uma relação de cooperação entre dois países como Brasil e França traz em seus meandros a necessidade de contextualização de aspectos contingentes a ambos os 
cenários, considerando pontos em comum constituintes das realidades brasileira e francesa, mas também especificidades desses contextos, principalmente no que se refere aos aspectos sociais e políticos das respostas, francesa e brasileira, diante da epidemia da aids.

A resposta brasileira à aids estabelece uma estreita relação com a forma como foi estruturado o sistema de saúde nacional. Essa articulação é sustentada pelo princípio que considera a saúde como um direito de todos e um dever do Estado, pautado pela Constituição de 1988, possibilitando vislumbrar a prevenção e o acesso a insumos também como um direito. Esse relevante marco na composição da história da saúde brasileira tem influências positivas na responsabilidade de cada um e do Estado no trabalho para a garantia da saúde, no entanto também revela facetas normativas que fazem do direito à saúde um item complexo da agenda política brasileira (Nogueira \& Pires, 2004).

O Sistema Único de Saúde (SUS) no Brasil fortaleceu as bases da noção de saúde em questão, trazendo benefícios à sociedade e dando origem a políticas públicas ancoradas nos princípios de universalidade, equidade, integralidade e descentralização. Nesse sentido, as estratégias de enfrentamento à aids no Brasil também se inserem nesse contexto, viabilizando, por exemplo, a adoção, desde 1996, de uma política pública de acesso universal ao tratamento antirretroviral, que se transformou em um marco na evolução da resposta brasileira à aids, com impacto, inclusive, no cenário internacional (Hallal, Ravasi, Kuchenbecker, Greco, \& Simão, 2010).

O direcionamento da política nacional de saúde se caracteriza como função do Ministério da Saúde do Brasil, porém, seguindo um modelo descentralizado, o Departamento de DST, Aids e Hepatites Virais é responsável pela coordenação da política de enfrentamento à epidemia. Nesse sentido, Estados e Municípios, pautados na ideia de descentralização do poder, têm certa autonomia em suas esferas de governo, com instâncias e diretrizes locais (Brasil, 2010).

De acordo com o Boletim Epidemiológico Aids e DST (Brasil, 2014), de 1980 até junho de 2014, foram identificados 491.747 (65,0\%) casos de aids em homens e 265.251(35,0\%) em mulheres. Algumas mudanças significativas ocorreram no cenário epidemiológico brasileiro, como as transformações com relação à razão de sexo, o crescimento de casos em heterossexuais, o aumento de casos em jovens, entre outras. Vale ressaltar que a epidemia da aids no Brasil se concentra em populações vulneráveis e, por mais que se encontre estabilizada, ainda atinge altos índices epidemiológicos (Brasil, 2010).

Segundo Relatório da Sessão Especial da Assembleia-Geral das Nações Unidas (Brasil, 2010), a vulnerabilidade ao HIV, no Brasil, está relacionada a vários 
fatores, como questões de gênero, orientação sexual, raça/etnia, escolaridade, renda, religião, entre outros. A noção de vulnerabilidade (Brasil, 2007) aborda características individuais, sociais e programáticas que se desdobram em uma maior ou menor exposição diante do problema.

$\mathrm{Na}$ França, a gestão do sistema de saúde cabe ao Estado, tendo este por finalidade garantir tanto o interesse público quanto a melhoria da saúde da população. No território francês, existem divisões administrativas que englobam cem Departamentos (dos quais quatro são ultramar, territórios franceses administrados fora do continente Europeu) e 26 regiōes (Sandier, Paris, \& Polton, 2004). Nesse contexto, a Alta Autoridade de Saúde (HAS) desempenha papel institucional fundamental de avaliação e promoção de produtos e práticas que visem à melhoria da qualidade de saúde.

Outro aspecto relevante do sistema de saúde francês são as Agências Regionais de Saúde (ARS), que têm como responsabilidade a definição e implantação da política de saúde, organização da assistência, garantia da segurança e prevenção na região. Por meio das articulações governamentais, o sistema de seguridade social financia a maior parte das despesas relacionadas aos cuidados assistenciais e cuidados médicos. Dessa forma, uma rede de cuidados de saúde é estabelecida com o intuito de coordenar e monitorar o acompanhamento de patologias na população, colaborando para que a política de saúde da França atingisse marcas exitosas, obtendo uma cobertura universal e qualidade na assistência prestada (França, 2011).

Com relação aos dados epidemiológicos do contexto francês, em 2013, 6.220 casos de aids foram identificados com o HIV (Cazein,et al., 2015). Quanto à incidência, os homens que fazem sexo com outros homens (HSH) representam a população mais atingida, com uma incidência anual de 1.000 casos por 100.000 . Considerando esse contexto, ações que se destinem ao público prioritário se mostram necessárias, não deixando de fortalecer ações de promoção do uso de preservativos e que considerem a saúde sexual de toda a população (França, 2010).

\section{ANALISANDO SEMELHANÇAS E DIFERENÇAS NO DESENHO DE POLÍTICAS PÚBLICAS DE PREVENÇÃO EM DIFERENTES CONTEXTOS}

No que se refere ao Brasil, as conquistas alcançadas no âmbito da aids e da saúde pública fortaleceram o lugar da política nacional nas discussões internacionais e na defesa dos direitos humanos. No entanto alguns desafios ainda existem, como diminuir o número de novas infecções, com ênfase em populações vulneráveis, e 
promover o acesso universal às ações de prevenção (Brasil, 2010). Nesse sentido, é fundamental que os esforços de prevenção sejam formulados e executados com base em uma perspectiva que respeite as especificidades de uma sociedade, apontando como estratégias que reforçam mecanismos de invisibilidade que se sustentam no preconceito e discriminação, fracassam, dificultando o acesso à saúde.

Dessa forma, é preciso considerar diferenças contextuais que influenciam em processos decisórios e na elaboração de estratégias de prevenção ao HIV/ aids, considerando que existem determinados contextos de vulnerabilidade que atravessam as realidades diferenciadas encontradas nos dois países. Nesse sentido, a vulnerabilidade programática, que se ancora no desenvolvimento de ações institucionais, é constituinte dos contextos de vulnerabilidade que vivenciamos na sociedade atual e reflete a demanda de políticas públicas que voltem a atenção para situações específicas, como é o caso da atenção às mulheres no Brasil e aos imigrantes na França (Ayres, 1996).

Sobre esse ponto, no Brasil, se analisarmos a perspectiva de casos de aids por sexo, uma significativa diminuição na razão de sexo (M:F) pode ser notada desde o início da epidemia até os dias atuais (Brasil, 2012a). No caso da França, uma das especificidades que deve ser considerada diz respeito aos imigrantes, que, segundo o Plan National (França, 2010), caracterizam-se por pessoas que vivem atualmente na França, mas que nasceram em um país estrangeiro. Em 2004, estimou-se que 4,5 milhóes de imigrantes com mais de 18 anos vivem na França, sendo 9,6\% da população total. Entre estes, 9\% são oriundos da África Subsaariana. No período de 2003 a 2008, os estrangeiros representaram quase a metade das descobertas de casos de aids na França (46\%), sendo que há uma particularidade relevante referente às mulheres de nacionalidade africana, cujas taxas de incidência são 69 vezes superiores às observadas na população heterossexual francesa (França, 2010).

Tais contextos que contemplam especificidades evidenciam a necessidade de problematização e análise dos fatores de vulnerabilidade que atravessam as respostas à epidemia nestes dois países. $\mathrm{O}$ conceito de vulnerabilidade aplicado à área da saúde remete a uma contextualização que envolve aspectos sociais e programáticos de cada realidade, para além de uma percepção apenas individual. No que se refere ao contexto brasileiro, fatores de vulnerabilidade atravessam de forma relevante aspectos como a dificuldade de acesso e informação, a situação socioeconômica das pessoas que vivem com HIV/aids, o papel executado pelas ONGs no panorama social brasileiro, a forma como mulheres e crianças são vistas no interior da epidemia da aids, entre outros aspectos que se desdobram 
em "problemas" que devem ser percebidos como políticos para que se tornem alvo de políticas públicas.

Dessa forma, tornam-se válidas proposições que busquem analisar diferentes contextos de aplicação de políticas públicas de prevenção à aids, assim como ações elaboradas em diversas conjunturas, no intuito de aproximar iniciativas relevantes e fomentar estratégias propositivas no âmbito da saúde pública, ampliando o grau de controle social de tais políticas.

\section{MÉTODO E DISCUSSÃO}

Para análise da política pública de enfrentamento ao HIV/aids nos dois países em questão, devido à delimitação do período de estágio, optou-se por concentrar a análise do contexto francês a partir do documento elaborado pela Direção Geral de Saúde intitulado "Plan National de Lutte contre le VIH/SIDA et les IST 2010/2014" (França, 2010), que se caracteriza como um material relevante, já que se configura como a principal ferramenta de programação de ações e orientação de estratégias no âmbito da aids no país. Dessa forma, o plano foi adotado como documento de referência da análise, mostrando-se uma alternativa estratégica e produtiva, tendo em vista que concentra uma série de ações de políticas públicas elaboradas para assistência, tratamento e prevenção à aids na França, assim como uma leitura situacional da epidemia no país.

Ao assumir tal posicionamento metodológico, contemplando o Plan National como o documento de referência, a pesquisa documental é tomada como modalidade científica, considerando que esta se caracteriza por um método de investigação que consiste na organização e tratamento de dados recolhidos em um ou mais tipos de documentos. Como complementação, foram realizadas reuniōes com atores sociais vinculados institucionalmente à formulação e execução de políticas no âmbito da aids, no intuito de avaliar os desdobramentos práticos das políticas elencadas no plano. No entanto as conversas não serão aqui abordadas, tendo em vista que tiveram caráter complementar de entendimento do contexto e não foram abordadas tecnicamente para a pesquisa.

O plano francês caracteriza-se como um documento que organiza diretrizes e ações a serem desenvolvidas pelas diversas áreas de trabalho relacionadas à aids na França, tendo como objetivo transformar radicalmente, no prazo de cinco anos, a dinâmica da epidemia da aids, reduzindo a mortalidade pelo HIV. Nesse contexto, o Plano se apresenta como estratégia facilitadora para as ARS se apropriarem das orientações nacionais com relação às DST/HIV/aids. 
Para que alcance o objetivo de reduzir a incidência de casos de aids, o plano é organizado em medidas que giram em torno de cinco eixos estratégicos:

a) prevenção, informação e educação para a saúde;

b) diagnóstico;

c) assistência médica;

d) assistência social e defesa dos direitos/luta contra a discriminação;

e) observação e pesquisa. $\mathrm{O}$ documento também se organiza considerando programas populacionais, ou seja, dispõe sobre as medidas apresentadas para populações específicas, dando maior visibilidade a estas no panorama geral do plano. Dentro dessa ótica, encontram-se no centro das atividades as populações de HSH, lésbicas, bissexuais e transexuais; imigrantes/estrangeiros e outras populações vulneráveis, como pessoas em regime de prisão, usuários de drogas e profissionais do sexo (personnes prostituées). Nesse contexto, a luta contra as discriminações em razão da soropositividade e pela orientação sexual, pela identidade de gênero e por questôes de origem também estão inclusas no plano. Na França, a prevenção das DST/HIV/aids é integrada a uma abordagem global de questões relacionadas à sexualidade, sendo o Institut National de Prévention et d'Éducation pour la Santé (INPES) o setor responsável pelas campanhas governamentais.

Partindo de um estudo cuidadoso do Plan National (França, 2010), foram levantados os enunciados que dão sustentação a formações discursivas relevantes no âmbito da aids na França e que pautam estratégias governamentais com base no referencial foucaultiano de análise do discurso (Foucault, 2009).

As ações propostas no plano têm características amplas de acesso à população, estando voltadas tanto para o público geral como para públicos específicos, respeitando singularidades e integrando-as a um contexto maior de atenção à saúde sexual. No entanto o documento ainda apresenta a noção de risco em suas citações, podendo abrir precedentes para voltarmos a discussões supostamente ultrapassadas, como à noção de "comportamento de risco" ou mesmo "grupos de risco". No Brasil, a denominação sobre o risco sofreu transformaçóes que acompanharam o cenário epidemiológico do país, passando do entendimento de "grupos de risco" para o conceito de "comportamento de risco" e, atualmente, o direcionamento para a discussão de "contextos de vulnerabilidade", que se 
configuram como determinantes da situação da epidemia de aids no Brasil (Ayres, 1997).

No documento francês (França, 2010), são facilmente encontradas enunciações como "groupe de vulnerabilite" (grupo de vulnerabilidade), "personnes ayant des comportements à risque" (pessoas tendo comportamento de risco), "comportements à risque" (comportamentos de risco), expressóes pautadas em índices epidemiológicos que apontam para uma epidemia marcadamente concentrada no público HSH e migrantes. Dessa forma, é possível conjecturar que a utilização de enunciaçóes como as acima citadas traduz um contexto no qual as políticas públicas são também segmentadas e direcionadas a públicos específicos, de forma a alcançar, de fato, a realidade da população atingida. Percebe-se, portanto, uma abordagem menos enfática de "contextos de vulnerabilidade" nas açôes francesas, se comparadas ao contexto brasileiro. Tal observação deve considerar as diferenças socioeconômicas e culturais entre os dois países, mas, ao mesmo tempo, contribui para a problematização de questões referentes ao direcionamento das ações de prevenção, assistência e tratamento no Brasil, e o questionamento acerca das estratégias governamentais de acesso às populações mais atingidas.

Nesse sentido, após análise das formaçōes discursivas do plano, é possível perceber que determinadas açôes são designadas como prioritárias para "públicos mais vulneráveis" (publics plus vulnerábles), como expresso no texto. De acordo com o documento, tais públicos são: HSH, lésbicas, bissexuais e transexuais (LBT), imigrantes/estrangeiros e pessoas em situação de detenção, usuários de drogas e profissionais do sexo (que são denominados no plano como "outras populações em situação de vulnerabilidade").

Como estratégia para efetuar o diagnóstico precoce desses públicos, foi adotado pelo governo francês o sistema "tripé diagnóstico" (França, 2010), caracterizandose como um conjunto de ações que se destinam ao desenvolvimento de um processo eficaz de testagem do HIV. Para tanto, foram elencadas três categorias de acesso à população com vistas a obter o maior alcance possível na cobertura diagnóstica. Assim, o primeiro pilar refere-se ao diagnóstico no sistema de saúde, realizado pelos profissionais de saúde, direcionado ao conjunto da população, independentemente da noção de risco de exposição. O segundo pilar trata do diagnóstico por pares, ou seja, a realização da testagem é feita em uma oferta comunitária, na qual se objetiva atingir as populações de forte incidência, mas que, por algum motivo, não se sentem confortáveis ou não têm acesso ao diagnóstico nos serviços de saúde e, a partir dessa ação, podem buscar o teste em ambientes que frequentam. Esse dispositivo ainda se encontra em processo de desenvolvimento na França e se destina primeiramente à população $\mathrm{HSH}$, mas 
também poderá atender a outras populações, caracterizando-se como uma ação potencial de ampliação das possibilidades de diagnóstico para o HIV. O terceiro pilar se refere ao dispositivo atual de diagnóstico, que, segundo o plano, deve ser fortalecido e reorganizado para ampliar sua eficiência, reafirmando os critérios de este ser gratuito e anônimo.

No Brasil, os testes para HIV são realizados nos Centros de Testagem e Aconselhamento (CTA), e atualmente há uma maior oferta de diagnóstico por meio do teste rápido, pautado pela campanha "Fique Sabendo", do Ministério da Saúde. Recentemente, a disponibilização dos testes rápidos também foi ampliada, em algumas regiōes, para a rede de atenção básica, atendendo às gestantes e seus parceiros sexuais. Iniciativas exitosas também podem ser encontradas junto às profissionais do sexo, com objetivo de trabalhar questôes relativas à prevenção e ao uso do preservativo.

Retomando o plano francês (França, 2010), outra estratégia que se destaca e na qual este se apoia pela primeira vez concerne ao que é denominado "prevenção combinada", (prévention combinée) que associa um conjunto de ferramentas que inclui medidas relacionadas à prevenção comportamental, aumento dos indicadores tradicionais de diagnóstico e tratamento antirretroviral, com o objetivo de reduzir a transmissão do HIV. Tal estratégia também intenciona fortalecer políticas estruturais de acesso aos serviços de saúde, promovendo uma atenção equânime e apresentando o tratamento também como uma estratégia de prevenção, ou seja, o medicamento é utilizado como veículo de diminuição da transmissão do vírus, o que ganha destaque em termos de ações de redução da infecção pelo HIV, pois percebe a diminuição da carga viral, como uma possibilidade de redução do risco caso o indivíduo não faça uso do preservativo.

Essa possibilidade de abordar o tratamento inserido no discurso sobre prevenção caracteriza-se como uma ação inovadora do plano, abrindo espaço para a discussão sobre o não uso do preservativo masculino ou feminino em todas as relações, mesmo este ainda sendo a tecnologia central de combate ao vírus no interior da grande maioria das estratégias apresentadas no plano. Essa perspectiva contradiz a ideia perpetrada por uma importante organização civil francesa, a ACT UP Paris, que defende o uso do preservativo em todas as relaçóes e integra fervorosos debates sobre a normatização dessa tecnologia de prevenção.

No Brasil, atualmente as ações governamentais também começam a caminhar nessa direção. Confirmações como as da Pesquisa de Conhecimentos, Atitudes e Práticas na População Brasileira, realizada em 2013 e publicada no site da UNAIDS, ${ }^{1}$ que apontam que $45 \%$ da população sexualmente ativa no país não 
usou o preservativo nas últimas relações casuais, mesmo apontando também que $94 \%$ da população diz saber que o preservativo é a melhor forma de prevenção ao vírus HIV, de certa forma, identificam os caminhos da política pública. Ou seja, o cenário brasileiro se organiza no sentido de compreender que é preciso assumir outras tecnologias de prevenção, aderindo à ideia da "prevenção combinada", desde 2010 pautada pelo Plano francês. O modelo de prevenção combinada no Brasil contempla o tratamento como prevenção $(\mathrm{TcP})$, que segue a lógica anteriormente abordada na análise do plano francês; a profilaxia pós-exposição (PEP), que se trata do manejo da medicação antirretroviral após uma situação de risco de contato com o vírus HIV; e a profilaxia pré-exposição (PrEP), ainda em fase de estudo, que propóe o manejo da medicação para as pessoas não infectadas pelo HIV, mas que se encontram em elevado risco de contato Associação Brasileira Interdisciplinar de AIDS (ABIA, 2011).

Como se pode perceber, a prevenção combinada no Brasil se concentra em tecnologias avançadas de prevenção; já no contexto francês, a prevenção combinada se caracteriza por um conjunto de açôes que vão do nível pessoal ao tecnológico, apontando uma diferença no direcionamento das políticas.

Nas ações propostas pelo documento (França, 2010), a partir da análise dos discursos que sustentam as lógicas de prevenção, há uma visível divisão entre as populaçōes ditas "sob risco" e a população geral, sendo que, para a população HSH e LBT, a necessidade do uso do preservativo é massificada, apontando que, nessas relações em particular (mas também em relações de pessoas vivendo com HIV com parceiros ocasionais), o uso do preservativo deve ser sistemático, retomando a possibilidade de discussão de que, em outras relações ou mesmo populaçôes (homens e mulheres heterossexuais e migrantes), o uso do preservativo não necessariamente precisaria ser sistemático. Surge, nesse ponto, a complexa discussão entre a universalidade e a particularidade das políticas, assim como o cuidado que se deve ter para que estas não contribuam para a manutenção de práticas discriminatórias. Nesse sentido, ficam algumas perguntas: seria a abordagem que considera o não uso do preservativo em todas as relações mais próxima da realidade atual? Ou o caminho continua sendo a reprodução da informação de um uso "universal" do preservativo? A segmentação e adoção de diferentes práticas discursivas sobre prevenção para diferentes populaçôes pode reproduzir a lógica da discriminação?

Vale lembrar que, no caso Brasil, vemos uma difusão do vírus (para além das populaçóes prioritariamente citadas no plano francês) em mulheres e um alto nível em heterossexuais, o que, na França, concentra-se na população migrante. Um exemplo dessa diferença contextual pode ser encontrada no eixo 1 do plano (medida 2), no qual se aponta que, para a prevenção, é necessário o uso do 
"preservativo (masculino e feminino) em todas as situações de relações sexuais com parceiros ocasionais ou então de relaçôes novas ou recentes" (França, 2010, p. 24). Nesse sentido, há uma diferença ao aproximarmos do contexto brasileiro, no qual índices epidemiológicos direcionam açôes e campanhas também para pessoas acima de 50 anos com relacionamentos ditos "estáveis".

No entanto há uma semelhança no que tange ao discurso que compõe as estratégias de prevenção nos dois países, tendo em vista que há uma valorização do discurso educativo/pedagógico na orientação sobre a adoção de comportamentos mais bem "adaptados" ao que é designado como saudável ou de "não risco" para a transmissão do vírus HIV, como se pode notar no objetivo do eixo 1 do plano, em que se visa a permitir à população "adotar comportamentos favoráveis para lutar contra a transmissão do HIV e das DST” (França, 2010, p. 20).

Há, portanto, certa vigilância sobre o que são percebidos como comportamentos "negativos" à saúde, ou seja, o risco em saúde funciona eficientemente como dispositivo de uma ordem para a regulamentação dos modos de vida e produção de sujeitos na contemporaneidade. Tais processos de vigilância e elaboração de estratégias pautadas na pedagogização de comportamentos têm como consequência um governo sobre os corpos. Para Fassin e Memmi (2004), esse governo dos corpos se caracteriza por "um quadro definido por códigos e regulamentos, normas e valores, relações de autoridade e de legitimidade, interaçôes com o Estado e com a lei” (p. 10), e está entremeado nos dispositivos da vida cotidiana que se refletem na política e no discurso preventivo no âmbito da aids, pautando condutas para os indivíduos evitarem agravos à saúde. De acordo com os autores, "inserido nas políticas públicas de saúde, esse discurso está no marco da 'estatização do biológico'” (Fassin \& Memmi, 2004, p. 126), instaurando uma ideologia de moralidade da saúde e do corpo.

Nesse sentido, as políticas públicas como ações que se destinam à vida dos indivíduos (Guareschi, Lara, \& Adegas, 2010), como estratégias governamentais e de governamentalidade que visam a atuar sobre uma determinada situação que afeta a população, acabam por tornar-se um dispositivo de regulamentação e controle investido de poder. A sexualidade, nesse âmbito, torna-se um potencial dispositivo dessa governamentalidade populacional, executada por meio de variados e complexos mecanismos regulamentadores. Essa perspectiva sobre as políticas públicas vai ao encontro da discussão foucaultiana sobre a inscrição dos conceitos de biopolítica e biopoder, em que o primeiro destaca os mecanismos de regulação da vida que incidem sobre as populações (tais como controle de natalidade, morbidade, mortalidade, longevidade e controle populacional); e o segundo marca a incidência do poder sobre a individualidade dos corpos, a gestão sobre a vida e, consequentemente, sobre a sexualidade (Foucault, 1998). 
Mesmo aproximando contextos diferentes, que são atravessados por aspectos culturais, financeiros, políticos e sociais, como a Europa e a América do Sul, é possível perceber que o desenho mundial feito pela Aids encontra semelhanças quando se trata de estratégias de enfrentamento, construindo um discurso preventivo sustentado pelo uso do preservativo e pelo governo dos corpos, práticas e comportamentos.

Não deixando de considerar, como apontam Mattos e Batista(2015), que "ao analisar uma política é preciso considerar primeiramente onde ela se insere na história geral, bem como reconhecer sua história específica” (p. 108), intentamos, neste artigo, trazer pontos de encontros e desencontros observados em uma experiência pontual, mas que podem ser trabalhados de forma a problematizar questôes pertinentes ao cotidiano brasileiro de práticas e políticas por meio de um vislumbramento de contextos diferenciados, mas que estão imersos na trajetória de luta contra a aids.

\section{CONSIDERAÇÕES FINAIS DE QUESTIONAMENTOS INICIAIS...}

Tentar traçar uma linha de proximidade entre contextos atravessados por diferenças historicamente estruturadas nem de longe parece uma tarefa fácil. Inserir-se em meandros de produção de políticas públicas no âmbito da aids também não. Muito menos esforçar-se no intuito de buscar respostas para questionamentos que se fazem cada vez mais presentes e numerosos. Porém se torna valiosa a possibilidade de, por uma análise pontual de discursos de políticas públicas de prevenção ao HIV/aids, conjecturar caminhos a partir da observação de diferentes realidades que possam contribuir para um melhor entendimento da dinâmica existente.

Na França, como no Brasil, a carência de recursos relativos à saúde, educação, informação e financeiros entre as pessoas que vivem com HIV também existe, no entanto essa realidade está muito mais relacionada à população de migrantes que se estabelece na França em busca de novas oportunidades de vida. Já no Brasil, tais fatores se estendem à grande parte da população, ou seja, tornam-se elementos estruturantes de contextos de vulnerabilidade social e programática que, muitas vezes, inviabiliza ações e dificulta o acesso à saúde.

Nesse caminho, a vivência no território francês, aliada à análise pontual de um documento oficial orientador de políticas, como é o caso do Plan National de Lutte Contre le VIH/SIDA et les IST, permitiu cotejar aspectos específicos relativos à constituição das estratégias e políticas públicas de prevenção ao HIV que constituem o discurso acerca da aids na França. 
Mattos e Batista (2015) ressaltam que "todo enunciado de política tem uma história, uma trajetória; um enunciado de política não aparece do nada" (p. 109) e, nesse sentido, conversam com a perspectiva de Foucault (2009) de que tais enunciados compõem formações discursivas que produzem posições de sujeito, operando por meio de complexas relações de poder. Dessa forma, pôdese observar que existem diferenças em meio aos enunciados que emergem do interior desses documentos e da prática das ações francesas que, de acordo com a perspectiva acima citada, são capazes de designar diferentes posições de sujeito no contexto da epidemia da aids.

No documento francês, há uma "demarcação" estratégica entre os públicos, ou seja, públicos que exercem comportamentos ditos "de risco" e públicos fora desse espectro, enquanto no Brasil, por longos anos (não deixando de ressaltar iniciativas que hoje tornam as ações mais específicas para cada público), a ideia de que a aids atinge a todos, sem distinção de classe, sexo, gênero ou idade, pautou ações de prevenção voltadas para o público geral. Em meio a tais articulaçōes, podemos especular qual a direção "mais eficaz" a ser seguida pelas políticas públicas de prevenção ao HIV/aids. Seria o enfoque de demarcação do público vulnerável ou "com comportamento de risco", válido como estratégia de ação para controle da epidemia, considerando os índices epidemiológicos específicos para cada território (neste caso, França e Brasil)? Ou tal abordagem iria de encontro ao objetivo de "desconstruir" a discriminação pelo HIV, ou seja, o discurso da política pública acabaria, em certos momentos, reproduzindo uma situação de discriminação/preconceito ao apontar quem estaria "mais exposto" ao risco por conta de suas práticas?

É importante lembrar que lutar contra a discriminação é um ponto constituinte das estratégias de ambos os países no enfrentamento à epidemia da aids, sendo esta por conta da soropositividade pelo HIV ou por orientação sexual e de identidade de gênero. No entanto surge o questionamento sobre até que ponto as próprias políticas, em seus discursos, acabam por (re)produzir determinados lugares de discriminação e exclusão.

Nesse sentido, este artigo se posiciona diante de um amplo campo de problematizaçôes relacionadas ao direcionamento das políticas públicas em HIV/aids no Brasil, trazendo à luz questões que atravessam as ações existentes, em meio à vivência de mais uma década de epidemia. Desse modo, a oportunidade de estágio por meio da Cooperação Técnica Brasil-França se torna uma possibilidade ímpar de explorar outras realidades e formas/padróes de enfrentamento à epidemia, compreendendo os meandros da formulação de políticas públicas e seus desdobramentos na prática de ações governamentais 
e não governamentais, colaborando para a ampliação de recursos de discussão acerca da temática.

Caminhamos, portanto, no sentido de produzir realidades por meio de políticas e, dessa forma, torna-se imperiosa a reflexão acerca de que verdades são produzidas e legitimadas para que, assim, se possa pensar em uma política de saúde que de fato alcance os contextos de vulnerabilidade que atravessam a sociedade. Mesmo sem muitas respostas para tantos questionamentos, sabemos que é preciso trabalhar para que o respeito à diversidade sexual e de gênero, $o$ acesso equitativo aos serviços de saúde, o funcionamento efetivo da interlocução entre as três esferas de gestão do SUS e a participação da sociedade civil na formulação de estratégias de ação de prevenção e promoção da saúde sejam garantidos e para que, em meio às nuances que constroem as políticas, sejam priorizados os interesses sociais. 


\section{REFERÊNCIAS}

Associação Brasileira interdisciplinar de AIDS. (2011). Prevenção combinada: barreiras ao HIV. Rio de Janeiro: ABIA.

Ayres, J. R. C. M. (1996). O jovem que buscamos e o encontro que queremos ser: a vulnerabilidade como eixo de avaliação de ações preventivas do abuso de drogas, DST e AIDS entre crianças e adolescentes. (Série Ideias, 29, 15-23). Recuperado a partir de http://www.crmariocovas.sp.gov.br/pdf/ideias_29_ p015-024_c.pdf

Ayres, J. R. C. M. (1997). Vulnerabilidade e aids: para uma resposta social à epidemia. Boletim Epidemiológico de São Paulo, 15(3), 2-4.

Brasil. Ministério da Saúde. (2007). Plano Integrado de Enfrentamento da Feminização da Epidemia da Aids e outras DST. Brasília: Ministério da Saúde.

Brasil. Ministério da Saúde. (2010). Resposta Brasileira 2008/2009 - Relatório de Progresso do País. Metas e Compromissos Assumidos pelos Estados-Membros na Sessão Especial da Assembleia-Geral das Naçōes Unidas sobre HIVIAids. UNGASS - HIVIAids. Brasília: Ministério da Saúde.

Brasil. Ministério da Saúde. (2012a). Boletim epidemiológico AIDS e DST. Brasília: Ministério da Saúde. Recuperado a partir de http://www.aids.gov. br/sites/default/files/anexos/publicacao/2012/52654/boletim_jornalistas_ pdf_22172.pdf

Brasil. Ministério da Saúde. (2012b). Relatório de progresso da resposta brasileira ao HIVIAIDS (2010/2011). Brasília: Ministério da Saúde.

Brasil. Ministério da Saúde. (2014). Boletim epidemilógico Aids/DST. Brasília: Ministério da Saúde.

Cazein, F., Pillonel, J., Le Strat, Y., Pinget, R., Le Vu, S., Brunet, S.,... Lot, F. (2015). Découvertes de séropositivité VIH et de sida, France, 20032013. Bulletin Épidémiologique Hebdomadaire (BEH), 2015(9-10), 152-161. Recuperado a partir de http://www.invs.sante.fr/beh/2015/9-10/2015_910_1.html

Fassin, D. \& Memmi, D. (2004). Le gouvernement des corps. Paris: Éditions de l'École des Hautes Études en Sciences Sociales. 
Foucault, M. (1998). História da sexualidade I: a vontade de saber. (20a ed.). Rio de Janeiro: Graal.

Foucault, M. (2009). A arqueologia do saber. (7a ed.). Rio de Janeiro: Forense Universitária.

França. Ministère de la Santé. (2010). Plan national de lutte contre le VIH/SIDA et les IST. Paris: Ministère de la Santé. Récupéré de http://www.sante.gouv.fr/ plan-national-de-lutte-contre-le-vih-sida-et-les-ist-2010-2014.html

França. Ministère des Affaires Sociales et de la Santé. (2011). Présentation et organigrammes. Ministère Encharge de la Santé. Paris: Ministère de la Santé. Récupéré de http://www.sante.gouv.fr/presentation-et-organigrammes.html

Guareschi, N. M., Lara, L. \& Adegas, M. (2010). Políticas públicas entre o sujeito de direitos e o homo œconomicus. Psico, 41(3), 332-339. Recuperado a partir de http://revistaseletronicas.pucrs.br/ojs/index.php/revistapsico/article/ view/8163/5854

Hallal, R., Ravasi, G., Kuchenbecker, R., Greco, D. \& Simão, M. (2010). O acesso universal ao tratamento antirretroviral no Brasil. Revista Tempus Actas em Saúde Coletiva, 4(2), 53-66. Recuperado a partir de http://www.tempusactas. unb.br/index.php/tempus/article/viewFile/791/778

Mattos, R. A. \& Baptista, T. W. F. (2015). Sobre política (ou o que achamos pertinente refletir para analisar políticas). In: R.A. Mattos \& T.W.F. Baptista (Orgs). Caminhos para análise das políticas de saúde. (pp. 82-149). Porto Alegre: Rede UNIDA. Recuperado a partir de http://historico.redeunida. org.br/editora/biblioteca-digital/serie-interlocucoes-praticas-experiencias-epesquisas-em-saude/caminhos-para-analise-das-politicas-de-saude-pdf

Nogueira, V. M. R. \& Pires, D. E. P. (2004). Direito à saúde: um convite à reflexão. Cadernos de Saúde Pública, 20(3), 753-760. Recuperado a partir de http://www.scielo.br/pdf/csp/v20n3/12.pdf

Programa Conjunto das Nações Unidas sobre HIV/AIDS. Prevenção Combinada. Brasília: UNAIDS, 2018. Recuperado a partir de https://unaids. org.br/prevencao-combinada/

Sandier, S., Paris, V. \& Polton, D. (2004). Systèmes de santé en transition. Copenhague: Bureau Régional de l'OMS pour l'Europe de la Part de l'Observatoire Européen des Systèmes et des Politiques de Santé. 